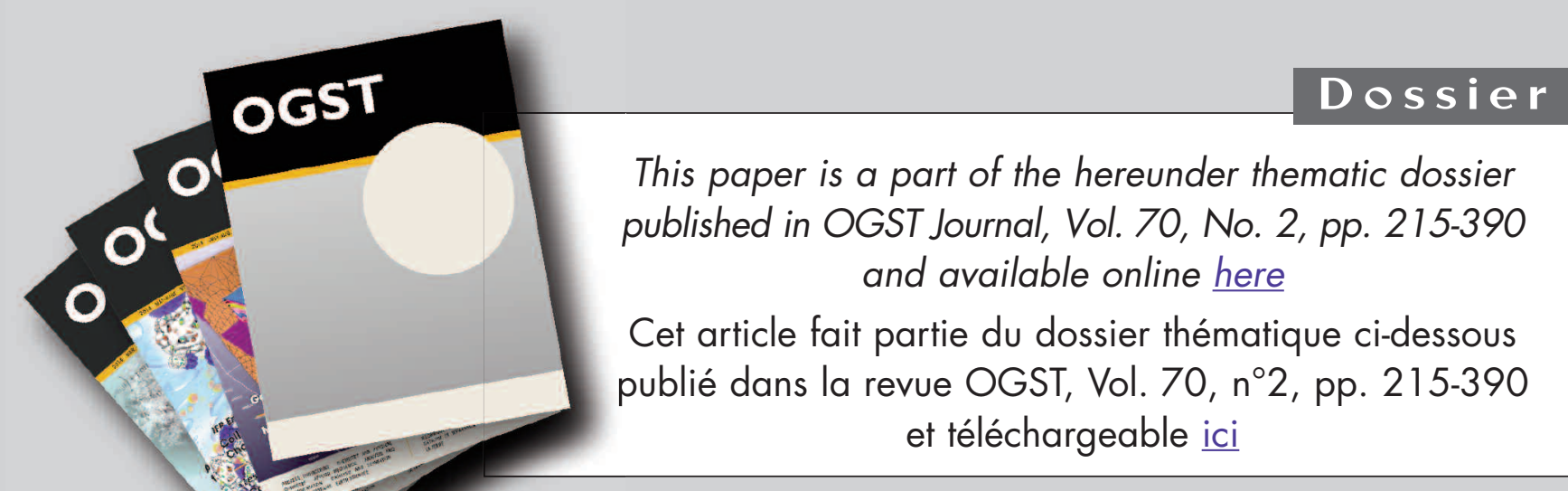

DOSSIER Edited by/Sous la direction de : B. Dewimille

Fluids-Polymers Interactions: Permeability, Durability

Interactions fluides polymères : perméabilité, durabilité

Oil \& Gas Science and Technology - Rev. IFP Energies nouvelles, Vol. 70 (2015), No. 2, pp. 215-390

Copyright (C) 2015, IFP Energies nouvelles

$215>$ Tribute to Yves Chauvin Hommage à Yves Chauvin

S. Candel and 0 . Appert

$219>$ Editorial

G. Kimmerlin

227 > Gas Permeation in Semicrystalline Polyethylene as Studied by Molecular Simulation and Elastic Model

Perméation de gaz dans le polyéthylène semi-cristallin par simulation moléculaire et modèle élastique

P. Memari, V. Lachet and B. Rousseau

237 > Reinforcement of the Gas Barrier Properties of Polyethylene and Polyamide Through the Nanocomposite Approach: Key Factors and Limitations

Renforcement des propriétés barrière aux gaz de matrices polyéthylène et polyamide par l'approche nanocomposite : facteurs clés et limitations E. Picard, J.-F. Gérard and É. Espuche

251 > Diffuso-Kinetics and Diffuso-Mechanics of Carbon Dioxide / Polyvinylidene Fluoride System under Explosive Gas Decompression: Identification of Key Diffuso-Elastic Couplings by Numerical and Experimental Confrontation

Cinétique de diffusion et comportement diffuso-mécanique du système dioxide de carbone / polyfluorure de vinylidène sous décompression explosive de gaz : identification des couplages diffuso-élastiques majeurs par confrontation numérique et expérimentale

J.-C. Grandidier, C. Baudet, S. A. E. Boyer, M.-H. Klopffer and L. Cangémi

267 > Characterization of Polymer Layered Silicate Nanocomposites by Rheology and Permeability Methods: Impact of the Interface Quality

Caractérisation de nanocomposites polymère silicate par des méthodes de rhéologie et de perméabilité : rôle de la qualité de l'interface

R. Waché, M.-H. Klopffer and S. Gonzalez

$279>$ Evaluation of Long Term Behaviour of Polymers for Offshore Oil and Gas Applications

Durabilité des polymères pour application pétrolière offshore

P.-Y. Le Gac, P. Davies and D. Choqueuse

$291>$ Development of Reactive Barrier Polymers against Corrosion for the Oil and Gas Industry: From Formulation to Qualification through the Development of Predictive Multiphysics Modeling

Développement de matériaux barrières réactifs contre la corrosion pour l'industrie pétrolière : de la formulation à la qualification industrielle en passant par le développement de modèles multiphysiques prédictifs

X. Lefebvre, D. Pasquier, S. Gonzalez, T. Epsztein, M. Chirat and F. Demanze
$305>$ Development of Innovating Materials for Distributing Mixtures of Hydrogen and Natural Gas. Study of the Barrier Properties and Durability of Polymer Pipes

Développement de nouveaux matériaux pour la distribution de mélanges de gaz naturel et d'hydrogène. Étude des propriétés barrière et de la durabilité de tubes polymères

M.-H. Klopffer, P. Berne and É. Espuche

317 > New Insights in Polymer-Biofuels Interaction

Avancées dans la compréhension des interactions polymères-biocarburants E. Richaud, F. Diouani, B. Fayolle, J. Verdu and B. Flaconneche

$335>$ Biofuels Barrier Properties of Polyamide 6 and High Density Polyethylene Propriétés barrière aux bio essences du polyamide 6 (PA6) et du polyéthylène haute densité (PEHD)

L.-A. Fillot, S. Ghiringhelli, C. Prebet and S. Rossi

353 > Permeability of EVOH Barrier Material used in Automotive Applications: Metrology Development for Model Fuel Mixtures

Perméabilité d'un matériau barrière EVOH utilisé dans des applications automobiles : développement métrologique pour des mélanges modèles de carburants

J. Zhao, C. Kanaan, R. Clément, B. Brulé, H. Lenda and A. Jonquières

367 > Effects of Thermal Treatment and Physical Aging on the Gas Transport Properties in Matrimid ${ }^{\circledR}$

Les effets du traitement thermique et du vieillissement physique sur les caractéristiques du transport au gaz dans le Matrimid ${ }^{\circledR}$

L. Ansaloni, M. Minelli, M. Giacinti Baschetti and G. C. Sarti

381 > Separation of Binary Mixtures of Propylene and Propane by Facilitated Transport through Silver Incorporated Poly(Ether-Block-Amide) Membranes Séparation de mélanges binaires de propylène et de propane par transport au travers des membranes de poly(éther-blocamide) incorporant de l'argent R. Surya Murali, K. Yamuna Rani, T. Sankarshana, A. F. Ismail and S. Sridhar 


\title{
Gas Permeation in Semicrystalline Polyethylene as Studied by Molecular Simulation and Elastic Model
}

\author{
P. Memari ${ }^{1,2}$, V. Lachet $^{2 *}$ and B. Rousseau ${ }^{1}$ \\ 1 Laboratoire de Chimie Physique, Université Paris-Sud, UMR 8000 CNRS, 91405 Orsay - France \\ 2 IFP Energies nouvelles, 1-4 avenue de Bois-Préau, 92852 Rueil-Malmaison - France \\ e-mail: peyman.memari@fmcti.com - veronique.lachet@ifpen.fr - bernard.rousseau@u-psud.fr \\ * Corresponding author
}

\begin{abstract}
Résumé - Perméation de gaz dans le polyéthylène semi-cristallin par simulation moléculaire et modèle élastique - Dans ce travail, nous utilisons la simulation moléculaire pour étudier la perméation de deux gaz $\left(\mathrm{CH}_{4}\right.$ et $\left.\mathrm{CO}_{2}\right)$ dans le polyéthylène. Ces simulations sont conduites à des températures inférieures à la température de fusion du polymère. Bien que dans de telles conditions, le polyéthylène soit à l'état semi-cristallin, des boîtes de simulation contenant exclusivement du polymère amorphe sont utilisées. Dans de précédents travaux [Memari P., Lachet V., Rousseau B. (2010) Polymer 51, 4978], nous avons montré que les effets de la morphologie complexe des matériaux semi-cristallins pouvaient être pris en compte de manière implicite par une contrainte ad-hoc exercée sur la phase amorphe. Dans le présent travail, nous montrons que cette approche peut être mise en œuvre non seulement pour le calcul de propriétés d'équilibre mais également pour le calcul de propriétés de transport comme les coefficients de diffusion. De plus, en utilisant le modèle élastique de Michaels et Hausslein [Michaels A.S., Hausslein R.W. (1965) J. Polymer Sci. : Part C 10,61], cette contrainte ad-hoc peut être reliée à la fraction de chaînes qui contribuent au terme d'énergie élastique dans le matériau. Nous constatons que les propriétés de transport dans les régions amorphes sont fortement influencées par cette fraction de chaînes.
\end{abstract}

\begin{abstract}
Gas Permeation in Semicrystalline Polyethylene as Studied by Molecular Simulation and Elastic Model - We have employed molecular simulation to study the permeation of two different gases $\left(\mathrm{CH}_{4}\right.$ and $\left.\mathrm{CO}_{2}\right)$ in polyethylene. The simulations have been performed at temperatures below the polymer melting point. Although under such conditions, polyethylene is in a semicrystalline state, we have used simulation boxes containing only a purely amorphous material. We showed in previous works [Memari P., Lachet V., Rousseau B. (2010) Polymer 51, 4978] that the effects of the complex morphology of semicrystalline materials on solubility can be implicitly taken into account by an ad-hoc constraint exerted on the amorphous phase. Here, it has been shown that our method can be applied not only for the calculation of equilibrium properties but also for transport properties like diffusion coefficients. In addition, the ad-hoc constraint has been theoretically related to the fraction of elastically effective chains in the material by making use of Michaels and Hausslein elastic model [Michaels A.S., Hausslein R.W. (1965) J. Polymer Sci.: Part C 10, 61]. We observe that the transport properties in amorphous regions are strongly governed by this fraction of elastically effective chains.
\end{abstract}




\section{INTRODUCTION}

In many areas of engineering, polymers are used as barriers to protect materials from gas or liquid contamination. For instance, polymers are used in food packaging, membrane separation processes, biomedical devices, offshore oil and gas production, etc. The relevant property for this process is the penetrant permeability which quantifies the flux of matter passing through the polymeric membrane. Permeability, $P e$, is the product of two terms: the solubility, $S$, describing the solute concentration into the polymer phase and the Fickian diffusion, $D$, describing the solute mass transport inside the polymer:

$$
P e=S \times D
$$

The knowledge of both solubility and Fickian diffusion coefficient (thereafter, called diffusion coefficient) is required for a complete description and understanding of permeability.

From an experimental point of view, there has been a large amount of work on the solubility and diffusion of small penetrants in polymers. Several techniques like gravimetry [1-4], permeation cell [5,6] and NMR [7] have been adopted to measure solubility and diffusion coefficients. From a theoretical point of view, these two quantities are usually described and calculated through the concept of free volume [8-10], the dual-mode transport model [11-14], and molecular theories [15-18].

Besides experiments and theory, molecular simulation is an attractive tool to calculate such properties. Molecular simulation, by describing the system at the molecular level, may reveal the microscopic mechanisms that play an important role in the barrier properties. Thanks to the increase of computing power and to new methodological developments, several authors have investigated the modeling of gas solubility in polymers at a molecular level. For example, Gusev and Suter [19] computed the infinite dilution solubility of methane in polycarbonate. Müller-Plathe [20] computed Henry's constant of different gases in amorphous atactic polypropylene by using a test particle insertion method similar to Widom's method [21]. Later, de Pablo et al. [22] employed Gibbs ensemble Monte Carlo simulations in order to compute the solubility of short chain alkanes in polyethylene melts beyond Henry's regime. Several studies have followed, considering many different penetrant gases and more complex polymers such as polystyrene [23], poly(styrene-alt-maleic anhydride) copolymer, pols-(styrene-stat-butadiene) rubber and atactic polystyrene [24], polyimide [25], polyamide [26], polyethylene terephthalate $[27,28]$.

In the early 1990s, Gusev et al. [29], Müller-Plathe [30, 31], Müller-Plathe et al. [32], Takeuchi [33], as well as Pant and Boyd [34], used molecular simulation to investigate the diffusion of small penetrants in polymers. Pant and Boyd [34] studied the transport properties of small penetrants in amorphous polyethylene and polyisobutylene. Gusev et al. [29] and Müller-Plathe et al. [30,32] used molecular dynamics method to show that gases diffuse through polymers in a sequence of activated jumps between neighboring locations (called hopping mechanism). By using the same method, van der Vegt [35] achieved to observe a transition temperature between hopping-like and liquid-like diffusion.

Despite considerable work on solubility and diffusion coefficients, computer simulation of both quantities beyond infinite dilution limit and using the same molecular model are rare. In this paper, we will compute simultaneously solubility and diffusion coefficients in order to evaluate the permeability. Furthermore, in most of the previous works mentionned above, transport properties have been obtained in melt or purely amorphous polymer or, in the case of semicrystalline materials, within the assumptions that:

- the amorphous phase is the only permeable phase;

- the amorphous phase characteristics are not affected by the presence of the crystalline regions.

The first assumption is strongly supported by experimental evidences. Experiments by Michaels and Bixler [5, 6] on different polyethylene grades with different degrees of crystallinity permitted to establish the following relationship between the solubility, $S$, and the diffusion coefficient, $D$, in the semicrystalline material versus the solubility and the diffusion coefficient in the amorphous phase (denoted by subscript $a$ ):

$$
\begin{array}{ccc}
S=S_{a}(1-\chi) & \text { with } & 0<\chi<1 \\
D=\frac{D_{a}}{\tau \beta} & \text { with } & \tau, \beta>1
\end{array}
$$

where $\chi$ is the (volume or mass) fraction of crystalline regions. In Equation (3), $\tau$ is a tortuosity factor accounting for the increase of the diffusion path caused by the presence of crystallites and $\beta$ is a chain immobilization factor which takes into account the reduction of the amorphous chain segment mobility due to the proximity of crystallites.

The second assumption is not always valid. In semicrystalline materials, the amorphous phase can be perturbed by the presence of crystallites. Thereby, several authors have reported large deviations between experimental data and theoretical predictions when they assume that the amorphous phase properties are not affected by the crystalline regions. Van der Vegt et al. [36] showed that gas solubilities in amorphous polyethylene, computed by molecular simulation, are 1.4 to 3.5 times greater than experimental values $\left(S_{a}\right)$ corrected from amorphous content (Eq. 2). Using another molecular model, Nath and de Pablo [37] found that the solubility of small molecules in amorphous polyethylene is overestimated, especially for highly soluble gases. $\mathrm{Hu}$ and Fried [38] also reported solubility coefficients of small gas molecules in poly(organophosphazenes) five times larger than what would be expected by extrapolating values 
reported for semicrystalline samples to a $100 \%$ amorphous material.

The crystalline region effect on the amorphous phase has been accounted for by theoretical approaches [39-41] based on Flory and Rehner work $[42,43]$. This effect comes from the fact that some polymer chains leaving a crystalline region may be trapped in another crystalline region. The network formed by these tie segments may constrain the amorphous regions of the polymer. This effect, called the elastic effect, has been invoked by several authors to correct the predicted solubilities by equations of state or group contribution methods [44-47] but was never accounted for in molecular simulations.

In a previous work [48], we were able to implicitly account for the effect of crystalline regions upon gas solubilities by using Monte Carlo simulations in the osmotic ensemble in an original way. We reproduced experimental solubilities by exerting an additional uniform constraint on our purely amorphous simulation box. A single constraint value emerged, independent of the gas nature, characteristic of the semicrystalline material. We concluded that the role of this ad-hoc constraint is to reproduce the effective density of the permeable phase of the material. This method has also shown its success toward the computation of gas mixture solubilities in semicrystalline polyethylene [49].

The methodology mentioned above has been applied to polyethylene (PE), because of its wide use in industrial applications and its relative simplicity as a molecular model. In the present work, we extend the proposed approach to permeability calculations in semicrystalline PE. Two different penetrants are investigated: carbon dioxide and methane, mostly chosen because of their relevance in gas production. The obtained results are then validated against experimental data.

This article is organized as follows. In the next section, we rapidly review the methodological aspects of this work. Section 2 discusses estimations of transport properties in the amorphous region of semicrystalline polymer from experimental data. In Section 3, we present our simulation results on gas solubility, gas diffusion coefficient and gas permeation. The increase of diffusion coefficient with gas concentration in polymer is captured. From the study of transport property temperature dependency, activation energies are calculated and compared with experiments. A link between the ad-hoc constraint used in our simulations and the elastic effect is then provided in Section 4. Finally, Section 5 summarizes our findings.

\section{METHODOLOGY}

We have employed Monte Carlo (MC) simulations in the osmotic ensemble to obtain the solubility of different gases in polyethylene. The details of these MC simulations are given elsewhere [48]. Molecular Dynamics (MD) simulations were performed in the canonical ensemble to obtain the diffusion coefficient of penetrants. Nosé-Hoover thermostat with an explicit time reversible integrator [50] has been used. A timestep of $2 \mathrm{fs}$ was used in our simulations. The carbon-carbon bonds in polyethylene were constrained to their equilibrium value $(1.535 \AA)$ using the Rattle algorithm [51].

Initial MD configurations are issued from the output of the osmotic ensemble MC simulations with number of penetrant molecules and volume equal to the average $\mathrm{MC}$ values. Initial particle velocities are taken from a Gaussian distribution. Self-diffusion coefficients, $D_{a}^{*}$, are computed from the mean square displacement $\operatorname{msd}(t)$ of the $N$ penetrant molecule center of mass positions, $r_{i}^{\mathrm{cm}}(t)$ :

$$
\operatorname{msd}(t)=\frac{1}{N} \sum_{i=1}^{N}\left[r_{i}^{\mathrm{cm}}(t)-r_{i}^{\mathrm{cm}}(0)\right]^{2}
$$

using the Einstein equation [52]:

$$
D_{a}^{*}=\frac{1}{6} \lim _{t \rightarrow \infty} \frac{d}{d t} \operatorname{msd}(t)
$$

For each system, the production run lasts $80 \mathrm{~ns}$. During this period, the mean displacement was larger than ten molecular diameters and we checked that penetrant molecules reached the diffusive mode (i.e. the linear regime of $\operatorname{msd}(t)$ ).

The polymer studied in this work is a model of linear polyethylene (PE) with 70 carbon atoms per chain. The force field and the mixing rule are identical to the ones used in our previous works $[48,49]$.

\section{ESTIMATION OF TRANSPORT PARAMETERS IN THE AMORPHOUS PHASE FROM EXPERIMENTS}

There are experimental measurements available for solubility and diffusion coefficients of gas in semicrystalline PE. However the simulations refer only to the amorphous part of the material, thus comparison of simulation results with experiments requires further elaboration.

Thanks to Equation (2), the conversion of measured solubility coefficients $S$ to solubility coefficients in amorphous phase $S_{a}$ is straightforward. The only required parameter is the crystallinity ratio $\chi$ which can be measured independently by several techniques (Differential Scanning Calorimetry (DSC), density measurement, Raman spectroscopy, Transmission Electron Microscopy (TEM) and Nuclear Magnetic Resonance (NMR) [53]).

The determination of the diffusion coefficient in the amorphous region, $D_{a}$, from experimental value $D$, is not straightforward. Parameters $\tau$ and $\beta$ involved in Equation (3) are not easily measured experimentally. Therefore, we could only obtain estimates for $D_{a}$ from three different methods.

In the first method, $D_{a}$ is extrapolated from the diffusion coefficient in polymer melts using the following equation:

$$
D_{a}=D^{\prime} \exp \left(-\Delta E_{d}\left(1 / T-1 / T^{\prime}\right)\right)
$$


where $T^{\prime}$ is a temperature above the polymer melting point, $D^{\prime}$ is the diffusion coefficient in polymer melt at $T^{\prime}, \Delta E_{d}$ is an activation energy for diffusion and $T$ is an arbitrary temperature below the melting point. We assumed that $\Delta E_{d}$ is constant over the whole temperature range.

The second method uses diffusion coefficient values in a $100 \%$ amorphous polymer grade. For polyethylene, there isn't a $100 \%$ amorphous grade at low temperature. Other polymers, such as natural rubber, are usually considered as its amorphous analogue [6]:

$$
D_{a} \simeq D^{\text {natural rubber }}
$$

The third method, proposed by Pant and Boyd [34], gives a lower bound for the diffusion coefficient using the following equation:

$$
D_{a} \geq \frac{3}{2(1-\chi)} D
$$

In the present work, we compare our simulation results with the values estimated from these three methods (Eq. 6-8).

\section{SIMULATION RESULTS}

In Figure 1, we present $\mathrm{CO}_{2}$ and $\mathrm{CH}_{4}$ concentrations in the amorphous phase of polyethylene at $293 \mathrm{~K}$ and $298 \mathrm{~K}$ respectively, obtained from Monte Carlo simulations in the osmotic ensemble. During these simulations, an additional isotropic constraint $\sigma_{\mathrm{PE}}$ of $80 \mathrm{MPa}$ is imposed on the simulation box to account for the effect of crystallites by reproducing the average density of the permeable phase [48]. As can be seen, a good agreement between simulation and experiments is observed. It is also shown that the gas concentration in polyethylene is linearly proportional to the pressure in this pressure range. In such cases, the Fickian diffusion coefficient $\left(D_{a}\right)$ is identical to the Maxwell-Stefan diffusion coefficient [54]. In addition, if the polymer chain mobility is neglected comparing to solute velocities, the Maxwell-Stefan diffusion coefficient can itself be approximated by the penetrant self-diffusion coefficient $\left(D_{a}^{*}\right)$. (For Fig. 1, see also [5,55-58]). Therefore, diffusion coefficient $D_{a}$ can be calculated from Equation (5). A $\operatorname{msd}(t)$ curve and its time derivative for $\mathrm{CO}_{2}$ diffusion in $\mathrm{PE}$ is given in Figure 2. The average diffusion coefficient is computed in the region where the slope of $\operatorname{msd}(t)$ is constant.

In Figures 3 and 4, we present the simulation results for $\mathrm{CO}_{2}$ diffusion at $293 \mathrm{~K}$ and $\mathrm{CH}_{4}$ diffusion at $298 \mathrm{~K}$. (For Fig. 3, see also $[6,7,59,60]$ and for Fig. 4, see $[6,61])$. It is shown that the use of an additional constraint of $80 \mathrm{MPa}$ on the amorphous box leads to a decrease of the diffusion coefficient. This observation is related to the increased density of the amorphous region under such an additional constraint, reducing gas mobility.

Experimental data are also reported in these graphs. Laguna et al. [7] reported two different experimental values

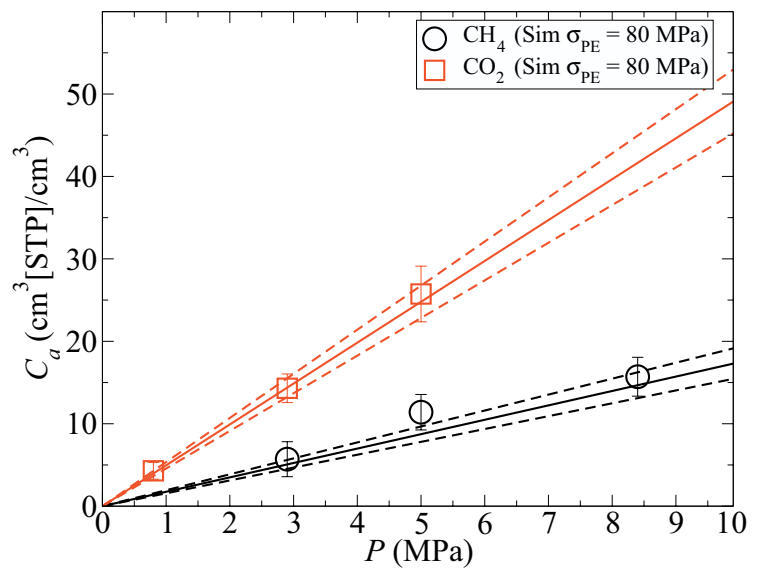

Figure 1

Dissolved gas concentrations as a function of pressure for $\mathrm{CO}_{2}$ and $\mathrm{CH}_{4}$, calculated by Monte Carlo simulations in the osmotic ensemble (at $298 \mathrm{~K}$ for $\mathrm{CH}_{4}$ and $293 \mathrm{~K}_{\text {for }} \mathrm{CO}_{2}$ ). Simulations are performed with an additional constraint of $80 \mathrm{MPa}$. Solid lines represent the average experimental concentrations from references [5,55-58] and dashed lines correspond to standard deviations from this average.

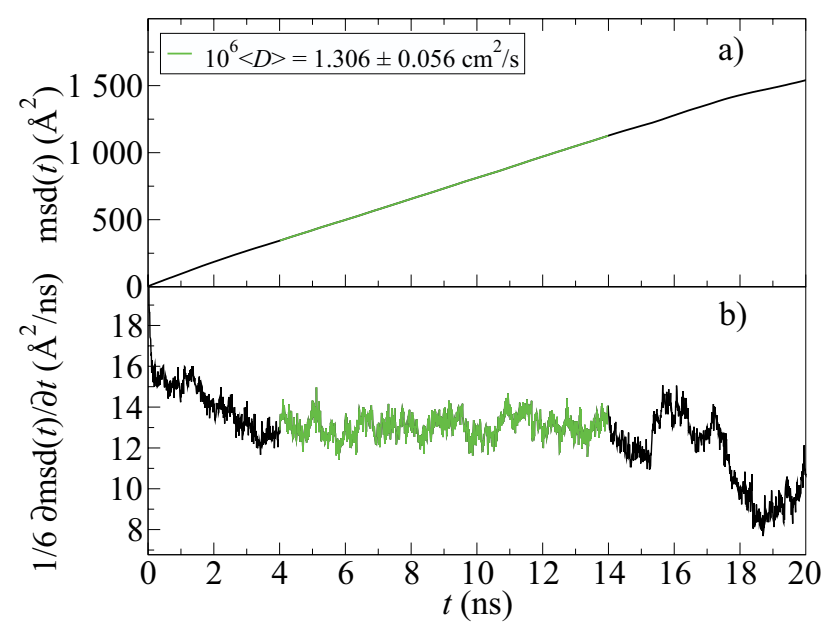

Figure 2

a) Mean square displacement and b) its time derivative versus time. The plots correspond to the simulation of $3 \mathrm{CO}_{2}$ molecules in 15 chains of $n \mathrm{C}_{70}$ at $293 \mathrm{~K}$ with an additional constraint of $80 \mathrm{MPa}$. The region where the slope of $\operatorname{msd}(t)$ is constant is in green.

for $\mathrm{CO}_{2}$ diffusion coefficient: a diffusion coefficient measured by permeation cell technique and a self-diffusion coefficient measured by NMR. The value obtained by NMR is an order of magnitude higher than the one obtained by permeation experiments. Except this NMR value and the estimate from the extrapolation method, all experimental values corrected either by Equation (7) or by Equation (8) are close to the simulation results obtained with an additional constraint of $80 \mathrm{MPa}$. This observation confirms the 


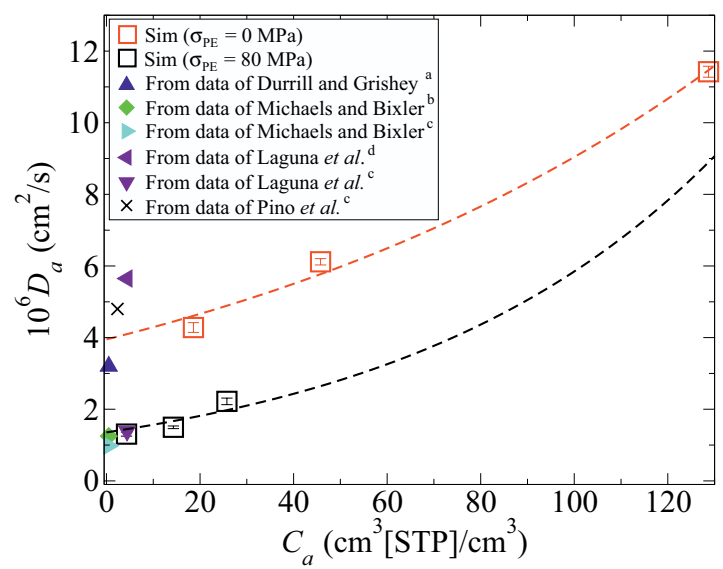

Figure 3

Diffusion coefficient of carbon dioxide versus concentration in the amorphous phase of PE at $293 \mathrm{~K}$. Two series of simulations are presented: with (black) and without (red) an additional constraint of $80 \mathrm{MPa}$. Dashed lines are exponential fits of the simulation results (Eq. 9). Experimental data are from Durrill and Griskey [59], Michaels and Bixler [6], Laguna et al. [7] and Pino et al. [60].

${ }^{a}$ Estimated from Equation (6), ${ }^{b}$ estimated from Equation (7), ${ }^{\mathrm{c}}$ estimated from Equation (8), ${ }^{\mathrm{d}}$ obtained by NMR experiment.

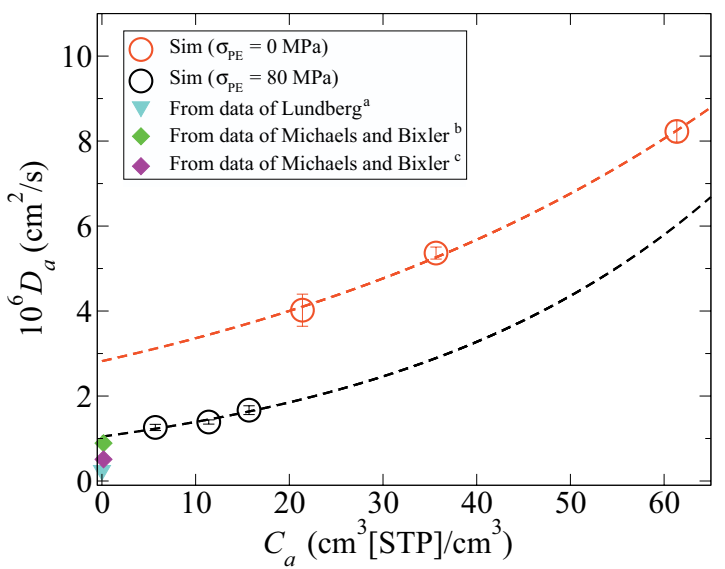

Figure 4

Diffusion coefficient of methane versus concentration in the amorphous phase of PE at $298 \mathrm{~K}$. Two series of simulations are presented: with (black) and without (red) an additional constraint of $80 \mathrm{MPa}$. Dashed lines are exponential fits of the simulation results (Eq. 9). Experimental data are from Michaels and Bixler [6] and Lundberg [61].

a Estimated from Equation (6), ${ }^{b}$ estimated from Equation (7), ${ }^{\mathrm{c}}$ estimated from Equation (8). need of an additional constraint to allow for a more realistic description of the amorphous region. It is also concluded that the extrapolation method is not reliable to estimate the diffusion coefficients at low temperatures. Main reasons are: - the diffusion activation energy is not constant with temperature;

- the effect of crystalline regions on the gas diffusion in the amorphous phase is completely ignored by the extrapolation approach.

We also observe that the diffusion coefficient increases with gas concentration in the polymer. This is related to the plasticization of polymer chains due to the presence of penetrant molecules. Vittoria [62] describes this behaviour using an exponential function:

$$
D_{a}=D_{a}^{\infty} \exp \left(\gamma C_{a}\right)
$$

In this relationship, $D_{a}^{\infty}$ refers to the diffusion coefficient at infinite dilution which is related to the fraction of free volume and $\gamma$ is the concentration coefficient which is a measure of the plasticization effect. $D_{a}^{\infty}$ and $\gamma$ values obtained from our simulation results are given in Table 1.

A diffusion slightly faster is obtained for $\mathrm{CO}_{2}$ compared to $\mathrm{CH}_{4}$. Such behaviour has been already reported in the literature with other polymers: polypropylene [63] and polystyrene [64], and has been interpreted on the basis of molecular structure considerations, attributing the faster diffusion to faster axial motions in case of linear molecules.

Finally, permeabilities have been computed from our molecular simulation diffusion and solubility coefficients.
TABLE 1

Diffusion coefficient at infinite dilution and concentration coefficient for carbon dioxide and methane in PE. The parameters are adjusted by fitting Equation (9) to simulation results

\begin{tabular}{cccc}
\hline & $T(\mathrm{~K})$ & $10^{6} D_{a}^{\infty}\left(\mathrm{cm}^{2} / \mathrm{s}\right)$ & $\gamma^{-1}\left(\mathrm{~cm}^{3}[\mathrm{STP}] / \mathrm{cm}^{3}\right)$ \\
\hline $\mathrm{CO}_{2}$ & 293 & 1.3 & 68.5 \\
$\mathrm{CH}_{4}$ & 298 & 1.0 & 35.5 \\
\hline
\end{tabular}

Calculated values are presented in Table 2 and shown in Figure 5 for the two studied gases. Data are in good agreement with experimental results of Michaels and Bixler at infinite dilution [6].

As the morphology of semicrystalline polyethylene evolves with temperature, we showed in our previous works $[48,65]$ that the additional constraint must decrease with increasing temperature: from $80 \pm 10 \mathrm{MPa}$ at room temperature $(293-298 \mathrm{~K})$ to $60 \pm 10 \mathrm{MPa}$ at $333 \mathrm{~K}$ and $40 \pm 10 \mathrm{MPa}$ at $353 \mathrm{~K}$. We have thus computed $\mathrm{CO}_{2}$ and $\mathrm{CH}_{4}$ solubility and diffusion coefficients at these three temperatures (see Tab. 2, 3) and we have then estimated activation energies for solubility, diffusion and permeability processes (see Tab. 4). Calculated activation energies are compared with experimental values of Flaconnèche et al. [66] and Michaels and Bixler [6]. The orders of magnitude are well reproduced. However, the activation energy for the diffusion process are slightly underestimated by our simulations. This difference can be related to the chain immobilization factor $(\beta)$ whose contribution 
to the activation energy is not taken into account in our simulations.

\section{TABLE 2}

Solubility, diffusion and permeability coefficients in PE amorphous phase for $\mathrm{CO}_{2}$ and $\mathrm{CH}_{4}$. The results are obtained by molecular simulations with an additional constraint of $80 \mathrm{MPa}$ applied on the amorphous phase

\begin{tabular}{lcccc}
\hline & $\begin{array}{c}P \\
(\mathrm{MPa})\end{array}$ & $\begin{array}{c}S_{a} \\
\left(\frac{\mathrm{cm}^{3}[\mathrm{STP}]}{\mathrm{cm}^{3} . \mathrm{MPa}}\right)\end{array}$ & $\begin{array}{c}10^{6} D_{a} \\
\left(\frac{\mathrm{cm}^{2}}{\mathrm{~s}}\right)\end{array}$ & $\begin{array}{c}10^{6} P e_{a} \\
\left(\frac{\mathrm{cm}^{3}[\mathrm{STP}]}{\mathrm{cm} . \mathrm{s} . \mathrm{MPa}}\right)\end{array}$ \\
\hline $\mathrm{CO}_{2}$ & 0.8 & $5.4 \pm 1.3$ & $1.3 \pm 0.1$ & $7.0 \pm 2.4$ \\
$(293 \mathrm{~K})$ & 2.9 & $4.9 \pm 0.6$ & $1.5 \pm 0.1$ & $7.3 \pm 1.5$ \\
& 5.0 & $5.1 \pm 0.7$ & $2.2 \pm 0.1$ & $11.2 \pm 2.1$ \\
$\mathrm{CH}_{4}$ & 2.9 & $2.0 \pm 0.7$ & $1.3 \pm 0.1$ & $2.6 \pm 1.2$ \\
$(298 \mathrm{~K})$ & 5.0 & $2.3 \pm 0.4$ & $1.4 \pm 0.1$ & $3.2 \pm 0.8$ \\
& 8.4 & $1.9 \pm 0.3$ & $1.7 \pm 0.1$ & $3.2 \pm 0.8$ \\
\hline
\end{tabular}

TABLE 3

Solubility, diffusion and permeability coefficients in PE amorphous phase for $\mathrm{CO}_{2}$ and $\mathrm{CH}_{4}$ at 333 and $353 \mathrm{~K}$. The results are obtained by molecular simulations with an additional constraint of $60 \mathrm{MPa}$ at $333 \mathrm{~K}$ and of $40 \mathrm{MPa}$ at $353 \mathrm{~K}$ applied on the amorphous phase

\begin{tabular}{cccccc}
\hline & $\begin{array}{c}T \\
(\mathrm{~K})\end{array}$ & $\begin{array}{c}P \\
(\mathrm{MPa})\end{array}$ & $\begin{array}{c}S_{a} \\
\left(\frac{\mathrm{cm}^{3}[\mathrm{STP}]}{\mathrm{cm}^{3} \cdot \mathrm{MPa}}\right)\end{array}$ & $\begin{array}{c}10^{6} D_{a} \\
\left(\frac{\mathrm{cm}^{2}}{\mathrm{~s}}\right)\end{array}$ & $\begin{array}{c}10^{6} P e_{a} \\
\left(\frac{\mathrm{cm}^{3}[\mathrm{STP}]}{\mathrm{cm} . \mathrm{s} . \mathrm{MPa}}\right)\end{array}$ \\
\hline $\mathrm{CO}_{2}$ & 333 & 5.0 & $4.1 \pm 0.2$ & $6.9 \pm 0.4$ & $28.3 \pm 3.1$ \\
$\mathrm{CO}_{2}$ & 353 & 5.0 & $4.0 \pm 0.2$ & $10.1 \pm 0.2$ & $40.4 \pm 2.9$ \\
$\mathrm{CH}_{4}$ & 333 & 5.0 & $2.3 \pm 0.3$ & $5.0 \pm 0.3$ & $11.5 \pm 2.3$ \\
$\mathrm{CH}_{4}$ & 353 & 5.0 & $2.4 \pm 0.2$ & $8.9 \pm 0.5$ & $21.4 \pm 3.0$ \\
\hline
\end{tabular}

\section{INTERPRETATION OF THE ADDITIONAL CONSTRAINT BASED ON THE ELASTIC MODEL}

The non crystalline regions of semicrystalline polymer are composed of elastically effective and elastically ineffective chain segments. The elastically effective chain segments consist exclusively of intercrystalline tie segments. The network formed by these tie segments has been considered as crosslinks constraining the amorphous phase of the polymer. This network results in an additional elastic constraint [39-41]. Several authors have invoked this elastic effect to correct their calculated gas solubility coefficients in the amorphous phase of semicrystalline polymers. The correction term is usually introduced as a contribution to the activity coefficients of the different species. Some modified equations of state are proposed that allow the calculation of thermodynamics properties including the elastic effect contribution [40, 44-47, 67].

Different elastic models exist in the literature. The Flory and Rehner model, which is dedicated to the study of crosslinks rubbers $[40,42,43]$, assumes a Gaussian distribution of the tie segments. A few years later, this model has been extended to semicrystalline polymers [39-41] considering a Hookean behaviour of the tie segments. Some authors have tried to compare these two elastic models $[44,47]$. Doong and Ho [44] showed that the model

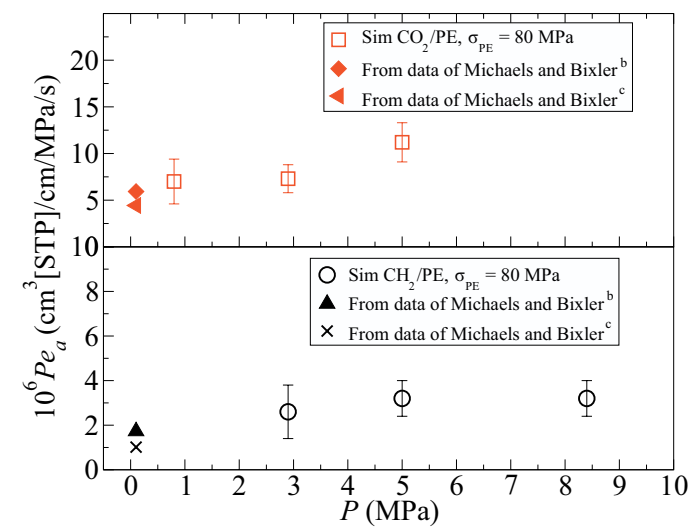

Figure 5

Permeability in PE amorphous phase for different pressures of carbon dioxide (top) and methane (bottom) at room temperature. Simulation results are obtained with an additional constraint of $80 \mathrm{MPa}$. Experimental data are from Michaels and Bixler [6]. ${ }^{\mathrm{b}}$ Estimated from Equation (7), ${ }^{\mathrm{c}}$ estimated from Equation (8).

proposed by Michaels and Hausslein [39], especially due to its temperature dependency, is more relevant in semicrystalline PE.

In the elastic model with Hookean segments, the energy cost associated with the stretching of an elastically effective tie segment is described by $[39,46]$ :

$$
\Delta U_{a}^{\text {elastic }}=K \frac{r^{2}}{2 u}
$$

where $r$ is the average distance between adjoining crystallites, $u$ the average number of methylene units in the tie segment and $K$ a spring constant. The force due to an elastically effective tie segment, $f_{a}^{\text {elastic }}$, is given by $-\nabla\left(\Delta U_{a}^{\text {elastic }}\right)$. By summing over all $v$ elastically effective segments, the total force on the polymer amorphous phase can be obtained:

$$
\mathbf{F}_{a}^{\text {elastic }}=-v \nabla\left(\Delta U_{a}^{\text {elastic }}\right)=-v \frac{K r}{u} \hat{\mathbf{r}}
$$

where $\hat{\mathbf{r}}$ is the unit vector in the $\mathbf{r}$ direction. The constraint on the amorphous phase due to the elastically effective tie segments is then:

$$
\sigma_{P E}=-\frac{1}{V_{a}}\left\langle\mathbf{F}_{a}^{\text {elastic }} . \mathbf{r}\right\rangle=\frac{1}{V_{a}}\left(v \frac{K r^{2}}{u}\right)
$$

where $V_{a}$ is the total volume of the amorphous regions.

Michaels and Hausslein [39] and more recently Banasazak et al. [46], based on the thermodynamic equilibrium between crystalline and amorphous phases, have shown the following relationship (see Eq. 26 in [39]):

$$
\frac{\bar{v}_{a}^{P} \nu K r^{2}}{3 V_{a} u}\left[1-\frac{3}{2 f \phi}\right]=-R T\left[\frac{\Delta H_{f}}{R}\left(\frac{1}{T}-\frac{1}{T_{m}^{\prime}}\right)\right]
$$


TABLE 4

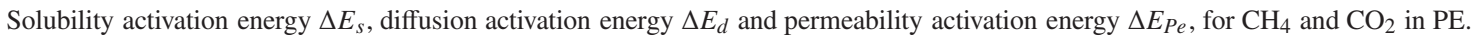
Comparison with experimental data of Flaconnèche et al. [66] and Michaels and Bixler [5, 6]

\begin{tabular}{l|ccc|ccc|ccc}
\hline & \multicolumn{4}{|c|}{$\Delta E_{s}(\mathrm{~kJ} / \mathrm{mol})$} & \multicolumn{3}{c|}{$\Delta E_{d}(\mathrm{~kJ} / \mathrm{mol})$} & \multicolumn{3}{c}{$\Delta E_{P e}(\mathrm{~kJ} / \mathrm{mol})$} \\
& This work & {$[66]$} & {$[5]$} & This work & {$[66]$} & {$[6]$} & This work & {$[66]$} & {$[6]$} \\
\hline $\mathrm{CH}_{4}$ & 1 & $3-4$ & $(-3)-2$ & 29 & $38-41$ & $43-46$ & 30 & $41-46$ & $40-47$ \\
$\mathrm{CO}_{2}$ & -4 & $(-2)-(-1)$ & $(-5)-0.5$ & 22 & $30-34$ & $36-38$ & 18 & $29-31$ & $30-39$ \\
\hline
\end{tabular}

where $\Delta H_{f}$ is the polymer molar heat of fusion, $\vec{v}_{a}^{P}$ the partial molar volume of polymer in the amorphous polymer phase, $\phi$ the volume fraction of polymer in the amorphous polymer phase, $T_{m}^{\prime}$ the melting point of crystallites in the presence of penetrant molecules and $f$ the fraction of elastically effective chains in the amorphous regions. Substituting Equation (13) into Equation (12), we obtain the following expression for the additional constraint:

$$
\sigma_{\mathrm{PE}}=\frac{3 R T}{\bar{v}_{a}^{P}} \frac{\left[\frac{\Delta H_{f}}{R}\left(\frac{1}{T}-\frac{1}{T_{m}^{\prime}}\right)\right]}{\left[\frac{3}{2 f \phi}-1\right]}
$$

It is interesting to note that Equation (14) predicts a nonzero constraint value even at zero penetrant concentration, i.e. for pure polymer. In this case, $\phi=1, \bar{v}_{a}^{P}=1 / \rho_{a}$ where $\rho_{a}$ is the number density of the pure amorphous region and $T_{m}^{\prime}=T_{m}$, the melting point of pure semicrystalline polymer. Equation (14) can thus be rewritten:

$$
\sigma_{\mathrm{PE}}=3 \rho_{a} R T \frac{\left[\frac{\Delta H_{f}}{R}\left(\frac{1}{T}-\frac{1}{T_{m}}\right)\right]}{\left[\frac{3}{2 f}-1\right]}
$$

In the following, we compare the values of $\sigma_{\mathrm{PE}}$ computed using Equation (15) with the values used in our molecular simulations. We recall that our constraint values were calibrated from comparison between experimental $\mathrm{CO}_{2}$ solubiliy coefficients on PE samples with crystallinity $\chi=50 \%$ and simulated values computed in the osmotic ensemble [48]. All quantities required in Equation (15), except $f$, have been taken from experimental results of Flaconnèche $e t$ al. obtained on a medium density polyethylene sample [66]. Few authors have reported values for the empirical factor $f$ in order to reproduce solubility data of penetrants in different PE samples [39, 44, 45, 47]. $f$ values are typically in the range 0.27-0.50. In Figure 6, we present the additional constraint value, $\sigma_{\mathrm{PE}}$, calculated from Equation (15) as a function of $f$ at $298 \mathrm{~K}, 333 \mathrm{~K}$ and $353 \mathrm{~K}$. At these temperatures, the additional constraint values used in our simulations are respectively $80 \pm 10 \mathrm{MPa}, 60 \pm 10 \mathrm{MPa}$ and $40 \pm 10 \mathrm{MPa}$ [48]. Figure 6 shows that a value of $f$, around $0.65-0.75$, can reproduce the additional constraints at all temperatures. This fraction of elastically effective chains is slightly larger than the values reported in the litterature. Such a large value might be related to the use of rather small chain lengths (70 carbon atoms) to model polyethylene. The use of longer chains would indeed lead to lower

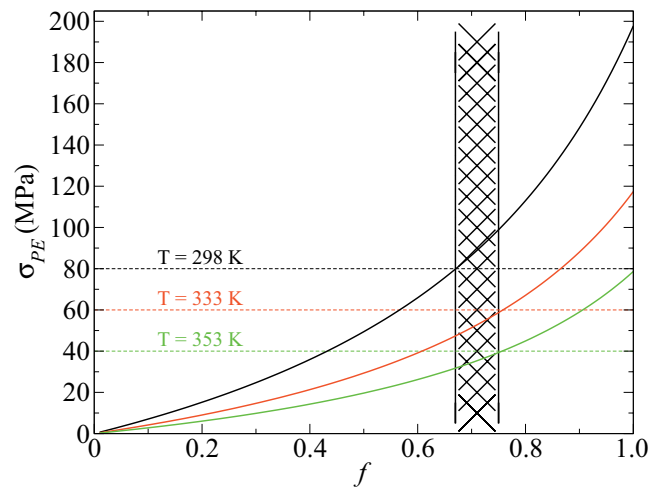

Figure 6

Additional constraint on the amorphous region versus fraction of elastically effective chains, $f$. The curves are obtained from Equation (15) for three different temperatures. Horizontal lines indicate the constraint values derived from molecular simulations. A single value of $f(0.65-0.75)$ allows to reproduce these constraint values at all temperatures (crossed zone).

additional constraint values, and thus to lower fractions of elastically effective chains.

\section{CONCLUSIONS}

We have shown in this work that our recently proposed technique based on osmotic ensemble Monte Carlo simulations [48] provides an effective method for evaluation of gas solubility in the amorphous phase of semicrystalline polymer. The real material density is reproduced when an $a d$-hoc constraint is applied to the polymer amorphous phase. This density value can then be imposed in molecular dynamics simulations without the use of a priori experimental results. The resulting diffusion coefficients are in good agreement with those obtained from experiments (Michaels and Bixler [6] among others).

Our methodology permitted the computation of the transport parameters (diffusion coefficient and permeability) of polyethylene amorphous region toward carbon dioxide and methane. The study of diffusion coefficient at different gas concentrations allowed us to capture the plasticization effect in polyethylene. In addition, we reproduced reasonable activation energies.

Elastic model of Michaels and Hausslein [39] is seen to be able to justify the effective constraint values employed in the simulations. It is shown that intercrystalline tie segments exert an additional constraint on the polymer 
amorphous phase, what should be accounted for in any molecular simulation of the amorphous phase. Our findings suggest that the fraction of elastically effective chains is independent of the gas pressure (in the range of 0-8 $\mathrm{MPa}$ ) or nature (for $\mathrm{CO}_{2}$ and $\mathrm{CH}_{4}$ ) or temperature (in the range of 293-353 K). Rather, it is a characteristic of the polymer with a given crystallinity and history. For this approach to be fully predictive, an a priori knowledge is required for this fraction of elastically effective chains.

\section{ACKNOWLEDGMENTS}

PM would like to thank IFP Energies nouvelles for financial support. Jean-Marie Teuler (Laboratoire de Chimie Physique) is gratefully acknowledged for support in code development.

\section{REFERENCES}

1 Ravens D.A.S., Ward I.M. (1961) Chemical reactivity of polyethylene terephthalate. Hydrolysis and esterification reactions in the solid phase, Trans. Faraday Soc. 57, 150-159.

2 Kamiya Y., Hirose T., Mizoguchi K., Naito Y. (1986) Gravimetric study of high-pressure sorption of gases in polymers, $J$. Polymer Sci. B: Polym. Phys. 24, 1525-1539.

3 Wong B., Zhang Z., Handa Y.P. (1998) High-precision gravimetric technique for determining the solubiliy and diffusivity of gases in polymers, J. Polymer Sci. B: Polym. Phys. 36, 20252032.

4 Chaudhary B.I., Johns A.I. (1998) Solubilities of nitrogen, isobutane and carbon dioxide in polyethylene, J. Cell. Plast. 34, 312-328.

5 Michaels A.S., Bixler H.J. (1961) Solubility of gases in polyethylene, J. Polym. Sci. 50, 393-412.

6 Michaels A.S., Bixler H.J. (1961) Flow of gases through polyethylene. J. Polym. Sci. 50, 413-439.

7 Laguna M.F., Guzmàn J., Riande E. (2001) Transport of carbon dioxide in linear low-density polyethylene determined by permeation measurements and NMR spectroscopy, Polymer 42, 4321-4327.

8 Vrentas J.S., Duda J.L. (1977) Diffusion in polymer-solvent systems. I. Reexamination of the free-volume theory, J. Polym. Sci.: Polym. Phys. Ed. 15, 403-416.

9 Vrentas J.S., Vrentas C.M. (1994) Solvent self-diffusion in glassy polymer-solvent systems, Macromolecules 27, 55705576.

10 Vrentas J.S., Vrentas C.M., Faridi N. (1996) Effects of solvent size on solvent self-diffusion in polymer-solvent sysems, Macromolecules 29, 3272-3276.

11 Vieth W.R., Sladek K.J. (1965) A model for diffusion in a glassy polymer, J. Colloid Sci. 20, 1014-1033.

12 Petropoulos J.H. (1970) Quantitative analysis of gaseous diffusion in glassy polymers, J. Polymer Sci. A-2: Polym. Phys. 8, 1797-1801.

13 Paul D.R., Koros W.J. (1976) Effect of partially immobilizing sorption on permeability and the diffusion time lag, J. Polym. Sci.: Polym. Phys. Ed. 14, 675-685.
14 Petropoulos J.H. (1990) Some fundamental approaches to membrane gas permeability and permselectivity, J. Membr. Sci. 53, 229-258.

15 Brandt W.W. (1959) Model calculation of the temperature dependence of small molecule diffusion in high polymers, $J$. Phys. Chem. 63, 1080-1085.

16 Pace R.J., Datyner A. (1979) Statistical mechanical model for diffusion of simple penetrants in polymers. I. Theory, J. Polym. Sci.: Polym. Phys. Ed. 17, 437-451.

17 Pace R.J., Datyner A. (1979) Statistical mechanical model for diffusion of simple penetrants in polymers. II. Applicationsnonvinyl polymers, J. Polym. Sci.: Polym. Phys. Ed. 17, 453464.

18 Pace R.J., Datyner A. (1979) Statistical mechanical model for diffusion of simple penetrants in polymers. III. Applicationsvinyl and related polymers, J. Polym. Sci.: Polym. Phys. Ed. 17, 465-476.

19 Gusev A.A., Suter U.W. (1991) Theory for solubility in static systems, Phys. Rev. A 43, 6488-6494.

20 Müller-Plathe F. (1991) Calculation of the free energy for gas absorption in amorphous polypropylene, Macromolecules $\mathbf{2 4}$, 6475-6479.

21 Widom B. (1963) Some topics in the theory of fluids, J. Chem. Phys. 39, 2808-2812.

22 de Pablo J.J., Laso M., Suter U.W. (1993) Simulation of the solubility of alkanes in polyethylene, Macromolecules 26, 61806183.

23 Eslami H., Müller-Plathe F. (2007) Molecular dynamics simulation of sorption of gases in polystyrene, Macromolecules $\mathbf{4 0}$, 17, 6413-6421.

24 Kucukpinar E., Doruker P. (2003) Molecular simulations of small gas diffusion and solubility in copolymers of styrene, Polymer 44, 3607-3620.

25 Neyertz S., Brown D. (2004) Influence of system size in molecular dynamics simulations of gas permeation in glassy polymers, Macromolecules 37, 10109-10122.

26 Eslami H., Mehdipour N. (2011) Grand canonical ensemble molecular dynamics of water solubility in polyamide-6,6, Phys. Chem. Chem. Phys. 13, 669-673.

27 Cozmuta I., Blanco M., Goddard W.A. III (2007) Gas sorption and barrier properties of polymeric membranes from molecular dynamics and Monte Carlo simulations, J. Phys. Chem. B 111, 3151-3166.

28 Eslami H., Müller-Plathe F. (2009) Water permeability of poly(ethylene terephthalate): A grand canonical ensemble molecular dynamics simulation study, J. Chem. Phys. 131, 234904.

29 Gusev A.A., Müller-Plathe F., van Gunsteren W.F., Suter U.W. (1994) Dynamics of small molecules in bulk polymers, $A d v$. Polym. Sci. 116, 207-247.

30 Müller-Plathe F. (1994) Permeation of polymers - a computational approach, Acta Polymerica 45, 259-293.

31 Müller-Plathe F. (1991) Diffusion of penetrants in amorphous polymers: A molecular dynamics study, J. Chem. Phys. 94, 3192-3199.

32 Müller-Plathe F., Laaksonen L., van Gunsteren W.F. (1993) Cooperative effects in the transport of small molecules through an amorphous polymer matrix, J. Mol. Graph. 11, 118-120.

33 Takeuchi H. (1990) A jump motion of small molecules in glassy polymers: A molecular dynamics simulation, J. Chem. Phys. 93, 2062-2067. 
34 Pant P.V.K., Boyd R.H. (1993) Molecular dynamics simulation of diffusion of small penetrants in polymers, Macromolecules 26, 679-686.

35 van der Vegt N.F.A. (2000) Temperature dependence of gas transport in polymer melts: Molecular dynamics simulations of $\mathrm{CO}_{2}$ in polyethylene, Macromolecules 33, 3153-3160.

36 van der Vegt N.F.A., Briels W.J., Wessling M., Strathmann H. (1996) Free energy calculations of small molecules in dense amorphous polymers. Effect of the initial guess configuration in molecular dynamics studies, J. Chem. Phys. 105, 8849-8857.

37 Nath S.K., de Pablo J.J. (1999) Solubility of small molecules and their mixtures in polyethylene, J. Phys. Chem. B 103, 3539-3544.

$38 \mathrm{Hu}$ N., Fried J.R. (2005) The atomistic simulation of the gas permeability of poly[bis(2,2,2-trifluoroethoxy)phosphazene], Polymer 46, 4330-4343.

39 Michaels A.S, Hausslein R.W. (1965) Elastic factors controlling sorption and transport properies of polyethylene, J. Polym. Sci. Polym. Lett. 10, 61-86.

40 Rogers C.E., Stannett V., Szwarc M. (1959) The sorption of organic vapors by polyethylene, J. Phys. Chem. 63, 1406-1413.

41 Rogers C.E., Stannett V., Szwarc M. (1960) The sorption, diffusion, and permeation of organic vapors in polyethylene, $J$. Polymer Sci. 45, 61-82.

42 Flory P.J., Rehner J. (1943) Statistical mechanics of crosslinked polymer networks I. Rubberlike elasticity, J. Chem. Phys. 11, 512-520.

43 Flory P.J., Rehner J. (1943) Statistical mechanics of crosslinked polymer networks II. Swelling, J. Chem. Phys. 11, 521-526.

44 Doong S.J., Ho W.S.W. (1991) Sorption of organic vapors in polyethylene, Ind. Eng. Chem. Res. 30, 1351-1361.

45 Serna L.V., Becker J.L., Galdámez J.R., Danner R.P., Duda J.L. (2008) Elastic effects on solubiliy in semicrystalline polymers, J. Appl. Polymer Sci. 107, 138-146.

46 Banasazak B.J., Lo D., Widya T., Ray W.H., de Pablo J.J., Novak A., Kosek J. (2004) Ethylene and 1-hexene sorption in LLDPE under typical gas phase reactor conditions: A priori simulation and modeling for prediction of experimental observations, Macromolecules 37 9139-9150.

47 Castro E.F., Gonzo E.E., Gottifredi J.C. (1996) The analysis of sorption data of organic vapors in polymeric membranes through novel theories, J. Membr. Sci. 113, 57-64.

48 Memari P., Lachet V., Rousseau B. (2010) Molecular simulation of the solubility of gases in polyethylene below its melting temperature, Polymer 51, 4978-4984.

49 Memari P., Lachet V., Klopffer M.-H., Flaconnèche B., Rousseau B. (2012) Gas mixture solubilities in polyethylene below its melting temperature: Experimental and molecular simulation studies, J. Membr. Sci. 390-391, 194-200.

50 Martyna G.J. (1996) Explicit reversible integrators for extended systems dynamics, Mol. Phys. 87, 1117-1157.
51 Andersen H.C. (1983) Rattle: A "velocity" version of the shake algorithm for molecular dynamics calculations, J. Comput. Phys. 52, 24-34.

52 Allen M.P., Tildesley D.J. (1987) Computer Simulation of Liquids, Clarendon Press, Oxford.

53 Hedenqvist M., Angelstok A., Edsberg L., Larsson P.T., Gedde U.W. (1996) Diffusion of small-molecule penetrants in polyethylene: Free volume and morphology, Polymer 37, 2887-2902.

54 Taylor R., Krishna R. (1993) Multicomponent Mass Transfer, John Wiley, New York.

55 Naito Y., Mizoguchi K., Terada K., Kamiya Y. (1991) The effect of pressure on gas permeation through semicrystalline polymers above the glass transition temperature, J. Polym. Sci. B: Polym. Phys. 29, 457-462.

56 Ash R., Barrer R.M., Palmer D.G. (1970) Solubility and transport of gases in nylon and polyethylene, Polymer 11, 421-435.

57 Togawa J., Horiuchi J., Kanno T., Kobayashi M. (2001) Freezepurged-desorption method for quantitative evaluation of $\mathrm{CO}_{2}$ solubility in polymeric films, J. Membr. Sci. 182, 125-128.

58 von Solms N., Nielsen J.K., Hassager O., Rubin A., Dandekar A.Y., Andersen S.I., Stenby E.H. (2004) Direct measurement of gas solubilities in polymers with a high-pressure microbalance, J. Appl. Polym. Sci. 91, 1476-1488.

59 Durrill P.L., Griskey R.G. (1969) Diffusion and solution of gases into thermally softened or molten polmers: Part II. Relation of diffusivities and solubilities with temperature pressure and structural characteristics, AIChE J. 15, 106-110.

60 Pino M., Duckett R.A., Ward I.M. (2005) Single and mixed gas diffusion through polyethylene films, Polymer 46, 4882-4890.

61 Lundberg J.L. (1964) Diffusivities and solubilities of methane in linear polyethylene melts, J. Polym. Sci. A: Gen. Pap. 2, 3925-3931.

62 Vittoria V. (1995) Influence of the crystallinity on the transport properties of polyethylene, J. Mater. Sci. 30, 3954-3958.

63 Müller-Plathe F. (1992) Molecular dynamics simulation of gas transport in amorphous polypropylene, J. Chem. Phys. 96, 3200-3205.

64 Mozaffari F., Eslami H., Moghadasi J. (2010) Molecular dynamics simulation of diffusion and permeation of gases in polystyrene, Polymer 51, 300-307.

65 Memari P. (2011) Perméation des Gaz dans les Polymères Semi-cristallins par Modélisation Moléculaire, $P h D$ Thesis, Université Paris-Sud 11.

66 Flaconnèche B., Martin J., Klopffer M.H. (2001) Permeability, diffusion and solubility of gases in polyethylene, polyamide 11 and poly(vinylidene fluoride), Oil Gas Sci. Technol. - Rev. IFP 56, 261-278.

67 Yao W., Hu X., Yang Y. (2007) Modeling solubility of gases in semicrystalline polyethylene, J. Appl. Polym. Sci. 103, 17371744.

Final manuscript received in October 2012 Published online in December 2013 